\title{
Comparison of Laboratory and In Situ Compressional- Wave Velocity Measurements on Sediment Cores From the Western North Atlantic
}

\author{
BRIAN E. TUCHOLKE \\ Lamont-Doherty Geological Observatory, Columbia University, Palisades, New York 10964
}

Donald J. Shirley

Applied Research Laboratories, University of Texas, Austin. Texas 78712

\begin{abstract}
Laboratory and in situ velocity measurements have been made on six piston cores taken in the western North Atlantic Ocean. Sediments from the southwestern Bermuda Rise and Greater Antilles Outer Ridge are clays having velocities ranging mostly from 1500 to $1530 \mathrm{~m} / \mathrm{s}$ and velocity gradients near $1 \mathrm{~s}^{-1}$. In cores from the Nares Abyssal Plain, the clayey sediments have comparable velocities, but interbedded silty turbidites exhibit much higher values (up to $1690 \mathrm{~m} / \mathrm{s}$ ). Velocity gradients are slightly higher in the abyssal-plain cores. After the laboratory measurements are corrected to in situ conditions, they show reasonable agreement in average velocity and velocity gradient with in situ measurements, although the in situ velocities average $10-12 \mathrm{~m} / \mathrm{s}$ higher in the clayey cores and $15-20 \mathrm{~m} / \mathrm{s}$ higher in the turbidites. This difference may be caused by reduction in the dynamic frame bulk modulus and/or the dynamic shear modulus due to visually undetected coring disturbance. The profilometer used to obtain the in situ measurements does not record the fine-scale variations in velocity that were measured in the laboratory, but it accurately determines average velocities and velocity gradient. Where cores were closely spaced (2$12 \mathrm{~km}$ apart), inter-core correlations in lithology, velocity, and bulk properties are possible. Fluctuations in the latter two parameters are very similar in position and magnitude from core to core, suggesting either that effects of coring disturbance are small or that they are uniform in a given kind of sedimentary bed. Inter-core comparison also shows that some beds are laterally discontinuous as a result of local (less than a few kilometers) patterns of seafloor erosion and deposition.
\end{abstract}

\section{INTRODUCTION}

Knowledge of the acoustic properties of the sea floor is important to the study of underwater propagation of sound. For a number of years the acoustic properties of sea-floor sediments have been determined primarily from seismic refraction and wide-angle reflection studies and from laboratory measurements of sound speed on samples recovered from the deep seafloor [e.g., Houtz and Ewing, 1963; Le Pichon et al., 1968; Hamilton, 1970a]. For samples measured in the laboratory, the in situ velocities are computed by correcting for pressure and temperature changes from in situ conditions. More recently, in situ measurements of sound velocity have been made in shallower-water surficial sediments by divers and from research submersibles [Hamilton et al., 1970].

Although these methods of determining acoustic properties of sediments are valuable, they do suffer several limitations. Seismic refraction and wide-angle reflection techniques are limited by uncertainties in the sound travel paths and velocity gradients as well as by the fact that they are averaged over a large volume of sediment. Use of probes by divers or submersibles has been limited to shallow penetration in fairly shallow water. A major limitation in correcting laboratory velocities of core samples to in situ values is the unknown effect of sediment disturbance caused by the coring process.

For the past 3 years the acoustic properties of deep ocean sediments have been measured routinely in situ using the compressional-wave sound speed profilometer developed at the Applied Research Laboratories of the University of Texas at Austin (ARL/UT) [Shirley and Anderson, 1975]. This instrument, described briefly below, has transducers mounted in the nose cone of a piston corer, and it obtains a continuous

Copyright (C) 1979 by the American Geophysical Union. record of compressional wave velocity of the sediments as the corer penetrates the seafloor. The instrument presently can be used in water depths up to $6800 \mathrm{~m}$, and the depth-in-sediment to which an in situ record is obtained is limited only by the penetration of the corer.

In 1976, we conducted a cooperative experiment aboard $\mathrm{R} / \mathrm{V}$ Conrad in the western North Atlantic Ocean in order to compare in situ compressional-wave velocities obtained with the ARL/UT profilometer to values measured in the laboratory and corrected to in situ conditions. Six piston cores were obtained that had sets of velocity data obtained by both methods; a seventh core has only laboratory measurements of velocity. In addition, the cores were sampled for physical properties and this information was compared to the measured velocities.

The experimental results show that although differences do exist between the two sets of velocity data, disagreement is generally $1 \%$ or less between in situ and corrected laboratory values for the overall profile. The principal differences between the two kinds of measurements are in the detailed structure of the profile, while the gross features of the profile (i.e., sound speed ratio and gradient) are essentially the same. The in situ profiles made by the profilometer do not measure thin beds which are detected in laboratory measurements, although the latter method does not accurately measure the sound speed of layers thinner than the probe spacing. Details of other smallscale variations in the profile are somewhat different for the two techniques, and a variation of about $10 \mathrm{~m} / \mathrm{s}$ about the mean is observed in laboratory measurements and a $5 \mathrm{~m} / \mathrm{s}$ variation is observed for in situ profiles.

The results reported here are a subset of velocity and physical properties data which we have obtained from cores taken in the western North Atlantic; laboratory measurements of 
compressional wave velocity and physical properties also have been made on 38 other piston cores and six gravity cores from varied morphologic and acoustic provinces in the basin, and they will be reported separately. All measurements are part of a continuing program to characterize the seafloor sediments according to compressional wave velocity, velocity gradient, bulk properties, and acoustic signature.

\section{METHODS}

\section{Coring}

Piston cores about 10-12 m long were taken using a standard Lamont-Doherty piston corer with the ARL/UT profilometer attached. Total weight of the corer was about 2000 lbs $(907 \mathrm{~kg})$ and free fall was $4.3 \mathrm{~m}$. Diameter of the cores is $6.35 \mathrm{~cm}$.

All cores were taken without liners and were extruded into trays after recovery. The cores were wrapped with an impermeable cover to prevent moisture loss and they normally were allowed to equilibrate with laboratory temperatures $2-4$ hours before sampling.

A short trigger-weight gravity core was taken with each piston core. Lithology of this core was compared to the accompanying piston core to determine how much, if any, surficial sediment had been lost from the piston core.

\section{ARL/UT Profilometer}

The profilometer was deployed on the piston corer for use during routine coring operations (Figure 1). The electronics package, battery power supply, and a cassette tape recorder are contained in a pressure housing tested to $10,000 \mathrm{psi}$. This housing was mounted on the core barrel just below the weight stand. Two transducers, resonant at $200 \mathrm{kHz}$, are mounted through holes drilled in the cutting edge of the corer. They transmit and receive a sound pulse across the diameter of the core as the core pipe penetrates the seafloor. The transducers are mounted as close as possible to the cutting edge to minimize the effect of sediment disturbance caused by penetration of the corer. Each transducer is connected to the electronics package via waterproof connectors and steel-armored cable which is attached to the outside of the core barrel. Another waterproof connector in the electronics package allows the instrument to be turned on at the surface, during deployment of the corer, by attachment of a shorting plug.

The signal outputs of the measuring electronics are recorded on an analog cassette tape recorder. The recorder operates in a four-channel FM mode at 17 ips and can record 1 hour of data on a C-120 cassette. One track of the tape records the sound speed data, one track records relative amplitude of the acoustic pulse, another track records the output of an accelerometer mounted inside the pressure housing, and the last track contains a constant reference frequency. During playback, the accelerometer output is integrated twice to provide a depth axis for the sound speed and pulse amplitude profiles. The reference frequency is utilized to compensate for tape-speed changes.

The electronics circuits measure the compressional wave velocity of whatever medium is between the fixed transducers by measuring the transit time of the $200 \mathrm{kHz}$ pulse through the medium. Thus the velocity measurements are made parallel to bedding planes in the sediment. The repetition rate of the 200 $\mathrm{kHz}$ pulse is 200 per second. For the $10-12 \mathrm{~m}$ cores discussed in this paper, the corer penetrated the sediment to total depth in $2-3 \mathrm{~s}$, so the average interval between measurements is about $2 \mathrm{~cm}$.

The profilometer is calibrated by measurement of delay times in various salt-water solutions of known velocity. Based on repeated calibrations, measured velocities are considered accurate to $\pm 4 \mathrm{~m} / \mathrm{s}$.

\section{Laboratory Velocimeter}

The instrument used to measure compressional wave velocities in the laboratory consists of two probes $3 \mathrm{~mm}$ thick and 27 $\mathrm{mm}$ wide, rigidly fixed $5 \mathrm{~cm}$ apart, which are attached to a drill-press stand and inserted into the core. Each probe con-

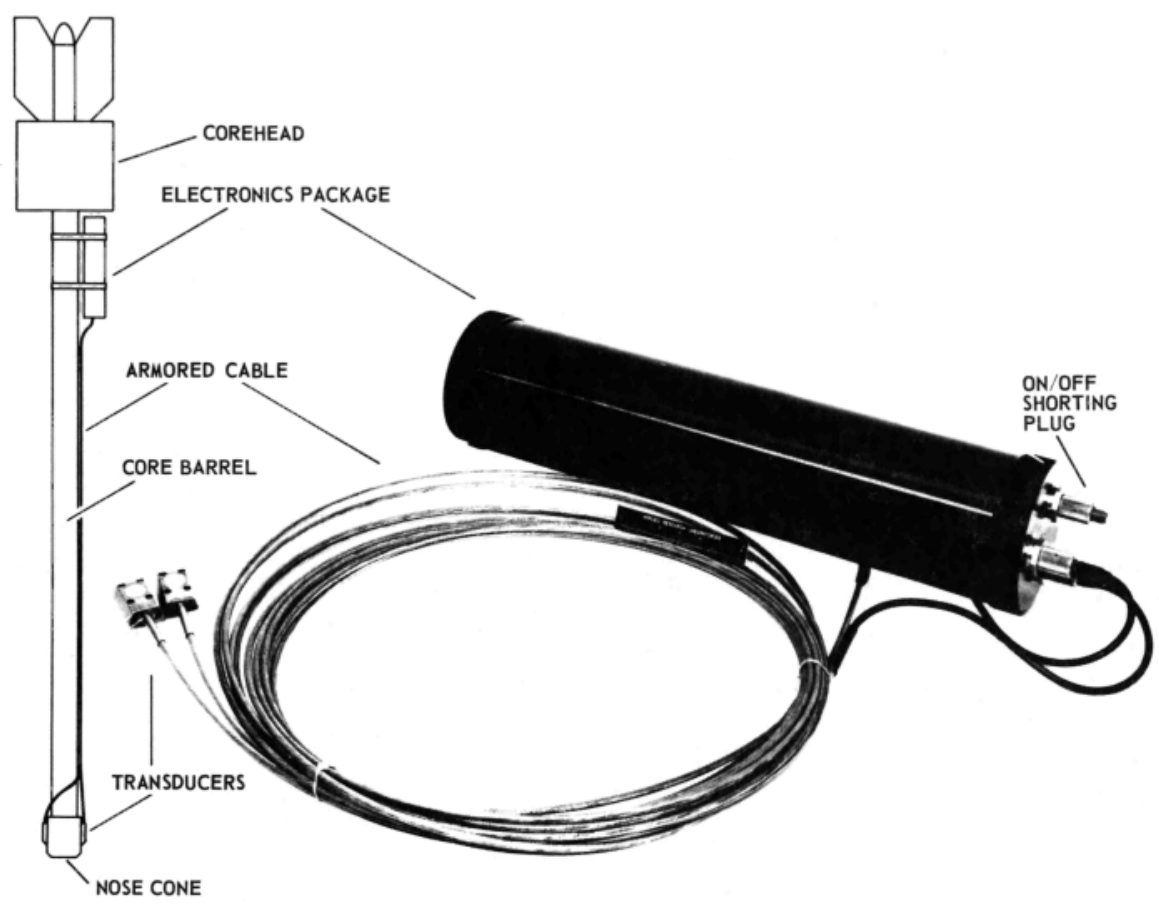

Fig. 1. ARL nose-cone compressional-wave profilometer. 
TABLE 1. Piston Cores Studied-Western North Atlantic

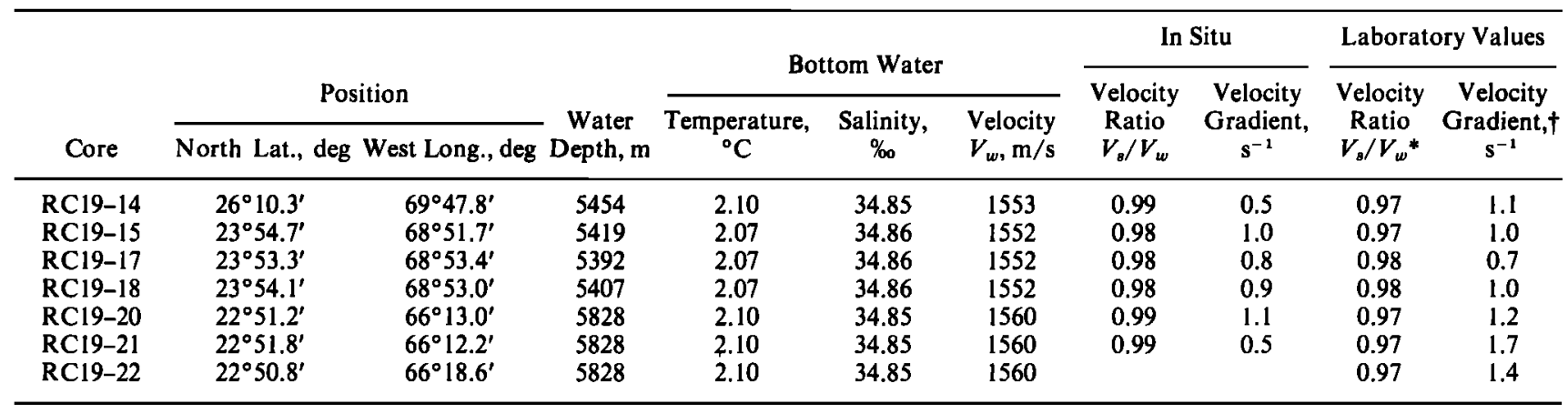

Laboratory values are corrected to in situ.

* Based on shallowest $(20 \mathrm{~cm})$ measurement in each core.

$\uparrow$ Based on least-squares fit of data points, exclusive of thin higher velocity beds.

tains a transducer resonant at $200 \mathrm{kHz}$, one transducer transmitting a pulse when excited by an attached pulse generator, and the other transducer receiving the signal. The pulse delay is proportional to the velocity of the medium being measured and is read from an attached oscilloscope. The velocimeter is calibrated in distilled water at varying temperatures and has an accuracy of $\pm 3 \mathrm{~m} / \mathrm{s}$.

After the cores were recovered, extruded, and allowed to equilibrate with room temperatures, velocity measurements were made at $20 \mathrm{~cm}$ or smaller intervals downcore, and temperature of the sediment at each measurement location was recorded. Measurement at each location was perpendicular to the bedding (parallel to the long axis of the core), although some additional measurements were made parallel to the bedding.

The laboratory values of velocity obtained in this manner were corrected to in situ conditions, using the method of Hamilton [1970b] and tables for the speed of sound in seawater [U.S. Naval Oceanographic Office, 1962]. In addition, the values were corrected downcore for an assumed thermal gradient of $0.06^{\circ} \mathrm{C} / \mathrm{m}$ in the sediment column.

\section{Physical Properties}

Syringe samples of 8-10 cc volume were taken at the same location as the velocity measurements. They were capped, sealed with wax, and refrigerated until they could be analyzed for physical properties in the shore laboratory. Physical properties determined from these samples include wet bulk density, water content, porosity and impedance. Corrections for porewater salinity of $35 \%$ were made on all samples.

\section{RESULTS}

Of the seven cores discussed here, one was recovered from the southwestern Bermuda Rise, three from the western Greater Antilles Outer Ridge and, three from the western Nares Abyssal Plain (Table 1, Figure 2). The three cores from the Greater Antilles Outer Ridge were taken within 2-4 km of one another in order to test the lateral uniformity of sedimentary layers and the representativeness of a given core, and to obtain intercore comparisons of acoustic and bulk properties. Similarly, the three cores from the Nares Abyssal Plain were taken within 2-12 km of one another. Figures 3-8 show data for six of the cores obtained in these areas. The in situ velocity data consists of corrected laboratory measurements plotted as connected points and in situ profilometer measurements plotted as a heavy solid line.

Cores from the Bermuda Rise and Greater Antilles Outer
Ridge consist of abyssal brown and gray clays with some beds of calcareous clay enriched in nannoplankton and foraminifera (Figures 3-6). Rates of sediment accumulation probably are 4-6 cm/ $1000 \mathrm{yr}$ for the outer ridge cores [Tucholke, 1975] and somewhat less on the Bermuda Rise. Cores from the Nares Abyssal Plain also are dominantly gray and brown clays, but they contain scattered silty and calcareous turbidite beds and laminae (Figures 7 and 8). Accumulation rates of these sediments probably are less than $3 \mathrm{~cm} / 1000 \mathrm{yr}$ [Tucholke, 1975].

Overall sound speed gradients for the cores as measured in the laboratory and in situ are generally similar (Figures 3-8, Table 1), although gradients trend toward slightly higher values in the laboratory measurements. Gradients near $1 \mathrm{~s}^{-1}$ typify the lithologically similar clays of the southwestern Bermuda Rise and Greater Antilles Outer Ridge. Somewhat higher gradients characterize the fine-grained turbidites and clays of the Nares Abyssal Plain, although this can not be demonstrated solely by the in situ measurements.

A significant difference between the two sets of velocity measurements is the consistently higher velocities measured in situ. The offset is about $10-12 \mathrm{~m} / \mathrm{s}$ for the Bermuda Rise and outer ridge cores with an increase to $15-20 \mathrm{~m} / \mathrm{s}$ for the Nares Abyssal Plain cores. The cause of this offset probably is not due to pressure and temperature effects on the mineral solids; these effects have not been considered when correcting laboratory values to in situ conditions, but they are insignificant [Hamilton, 1970b]. A possible explanation is that coring dis-

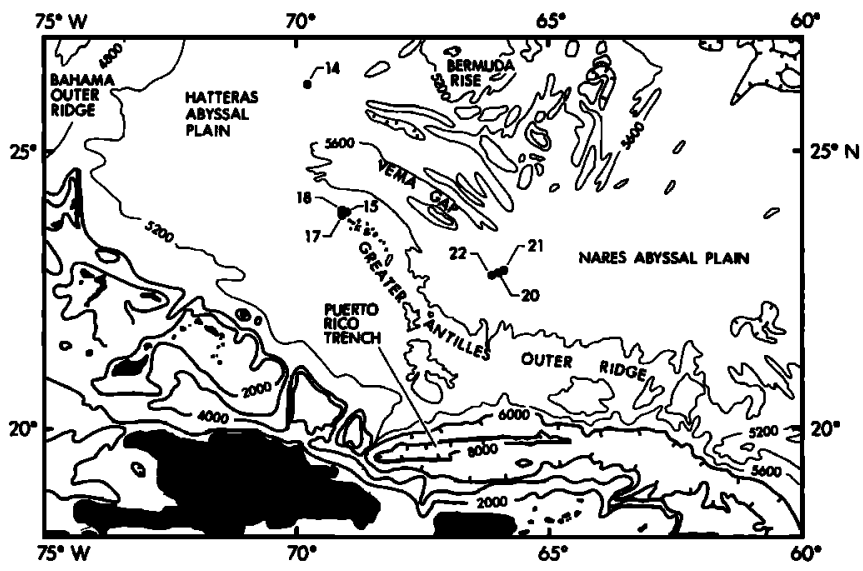

Fig. 2. Location of piston cores in western North Atlantic. Contours in corrected meters. 

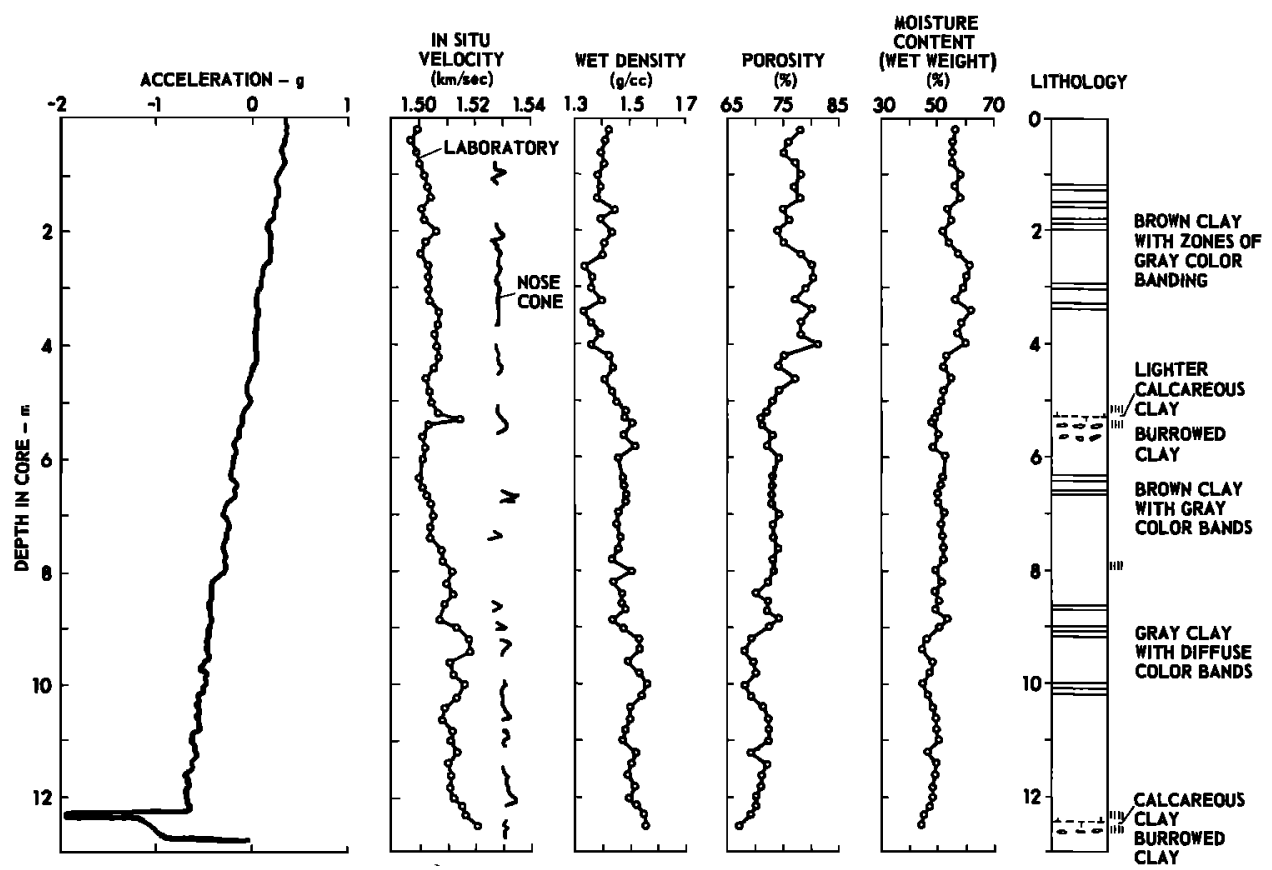

Fig. 3. Measured parameters for core RC19-14 from the southwestern Bermuda Rise. Explanation in Figure 5.

turbance has reduced the in situ dynamic frame bulk modulus $k_{f}$ and the dynamic shear modulus $G$ to some lower value, and thus correspondingly has reduced the compressional wave velocity. Shirley and Anderson [1976] showed that with a frame bulk modulus equal to zero, compressional wave velocities would be reduced about $5-15 \mathrm{~m} / \mathrm{s}$ in clay- and silt-size sediments, respectively, and that a reduction of the shear modulus to zero would cause a further decrease of $36-89 \mathrm{~m} / \mathrm{s}$ in compressional wave velocities.

If this effect accounts for the observed differences it is likely that, while the frame bulk modulus and shear modulus may not be reduced to zero, they are lowered to some threshold value beyond which further distortion has little effect. This is suggested by velocities of several samples that were measured in an undisturbed and remolded state (Table 2). Extensively remolded clayey samples from this short gravity core show no significant changes from 'undisturbed' samples in acoustic and bulk properties. The results of these and other measurements of velocity in clayey sediments also show that there is no significant velocity anisotropy which could account for the nose-cone velocities (measured parallel to the beds) being higher than the corrected laboratory velocities (measured perpendicular to the beds).

The velocity offset also could be caused by interstitial gas in

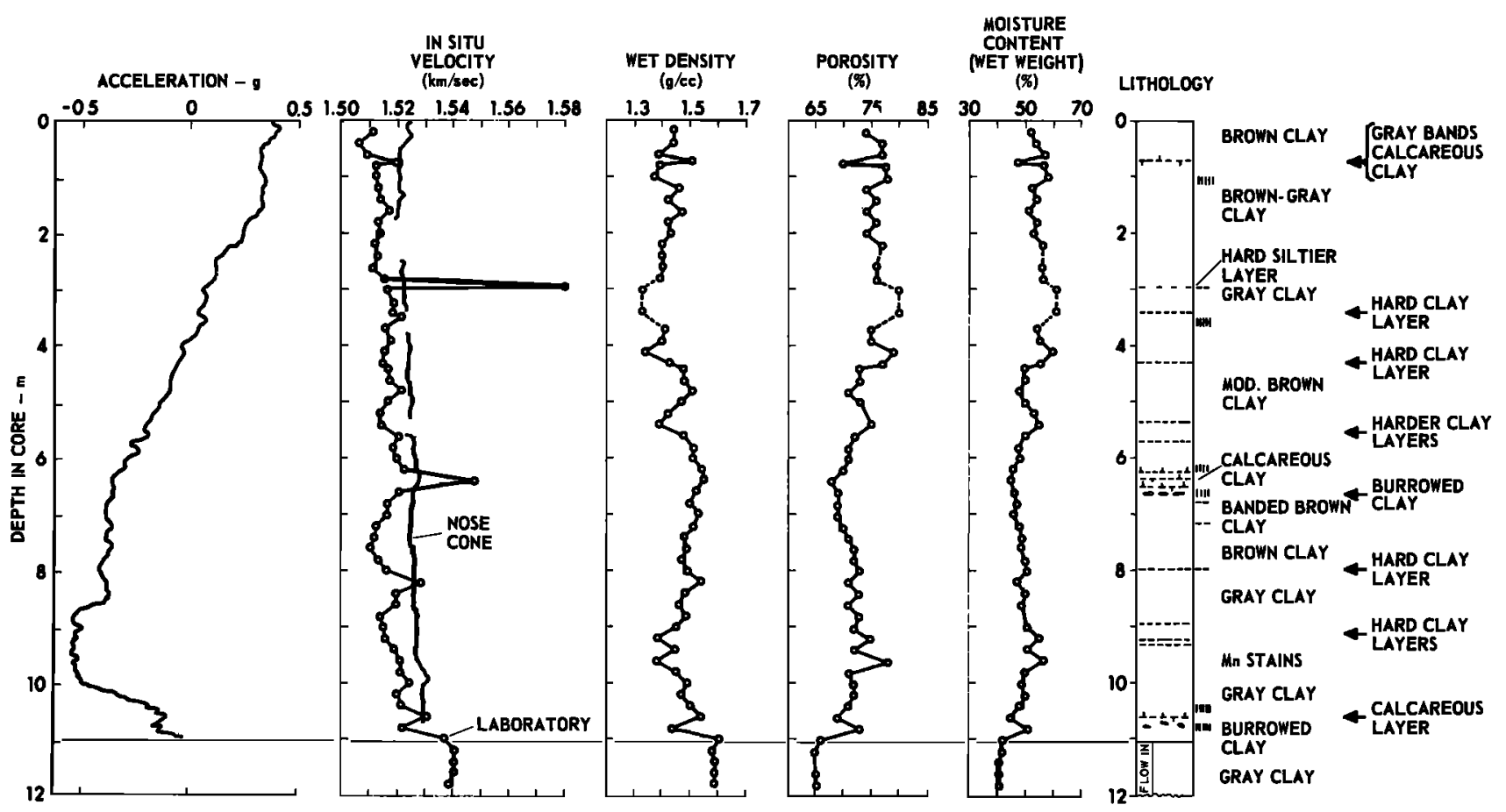

Fig. 4. Measured parameters for core RC19-15 from the Greater Antilles Outer Ridge. Explanation in Figure 5. 


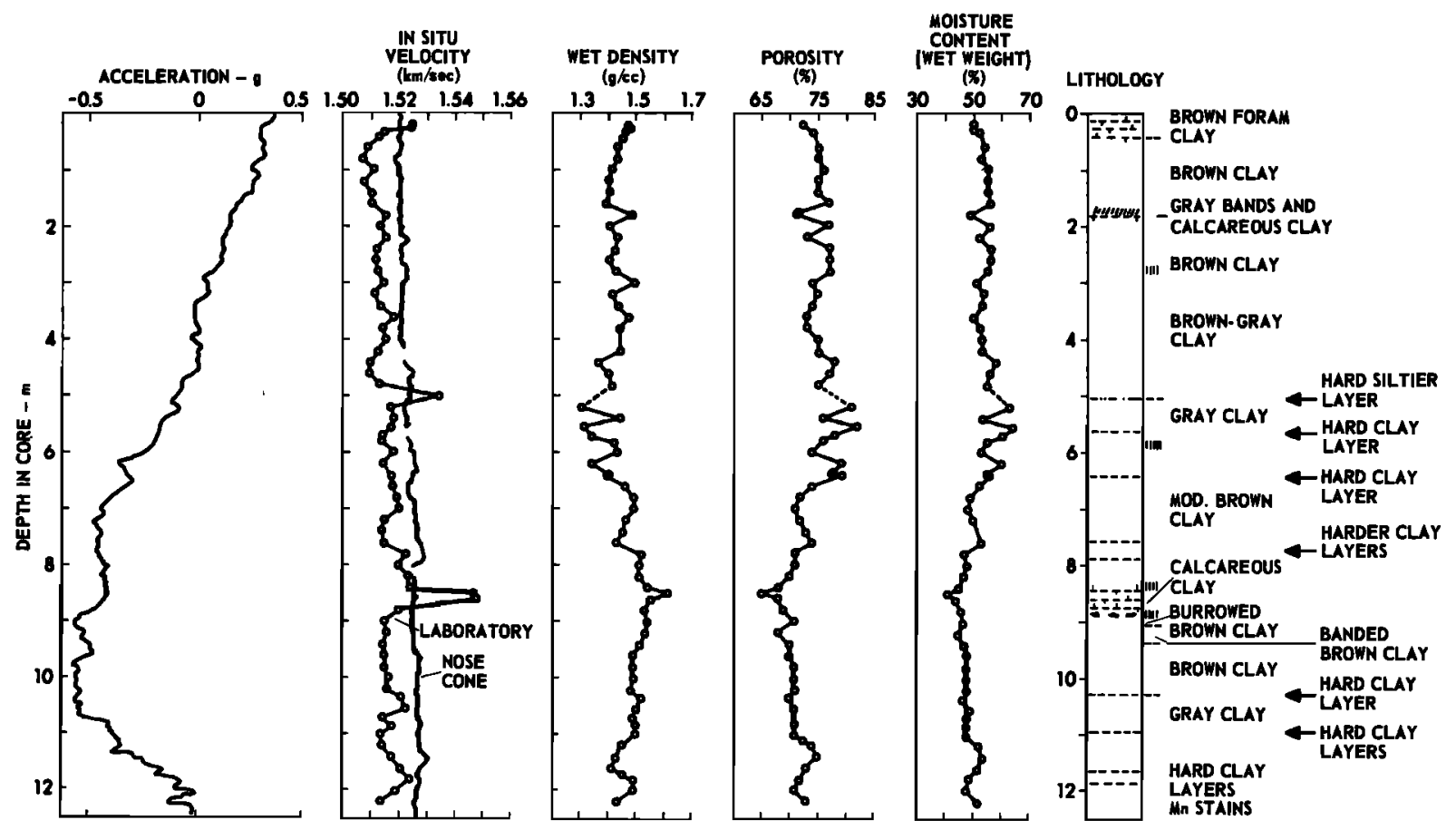

Fig. 5. Measured parameters for core RC19-17 from the Greater Antilles Outer Ridge. Laboratory velocities are corrected to in situ as explained in text. Dashed lines indicate levels where velocities were measured but no physical properties samples were taken. Sample points shown as solid dots are samples at slightly different depths from velocity measurements (e.g., where silt beds were too thin to sample completely). Hachures beside lithology column indicate transitional color changes; dashes indicate sharp color boundaries.

the cored sediment. When cores are raised to the surface, the expansion of small quantities of gas would effectively decrease the measured laboratory velocities. However, such effects presumably would not be as constant downcore as the observed velocity offsets are, and the cores showed no visible signs of degassing or any gas odors. Ultimately, the potential effect of interstitial gasses will have to be tested by measuring core samples both under laboratory conditions and in a repressurized state.

Another major difference between laboratory and profilometer measurements is that the profilometer measurements exhibit numerous data dropouts, shown as blank spaces on the velocity profiles of Figures 3-8. The gaps are areas where data is deleted from the profile because the pulse amplitude record

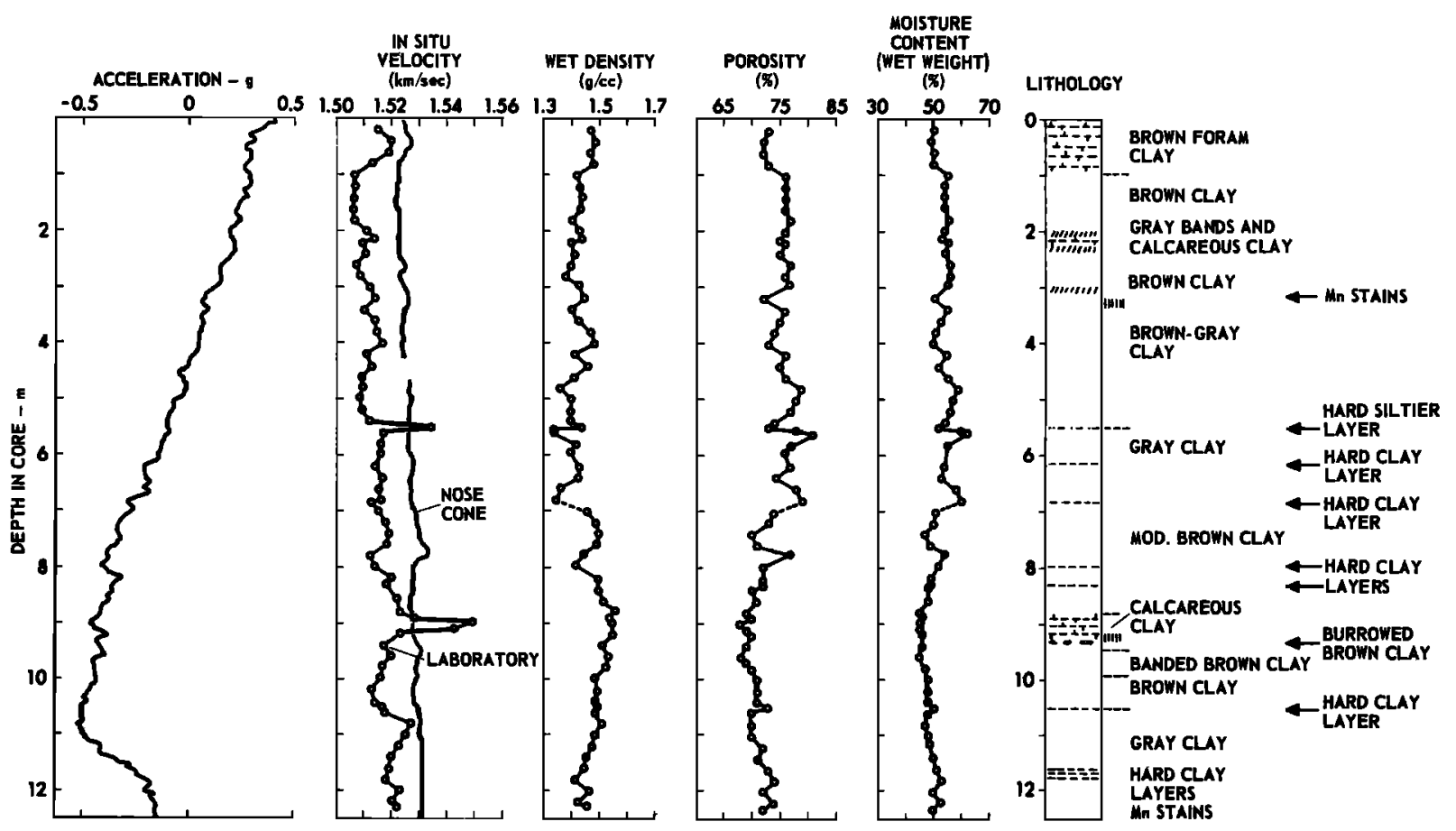

Fig. 6. Measured parameters for core RC19-18 from the Greater Antilles Outer Ridge. Explanation in Figure 5. 

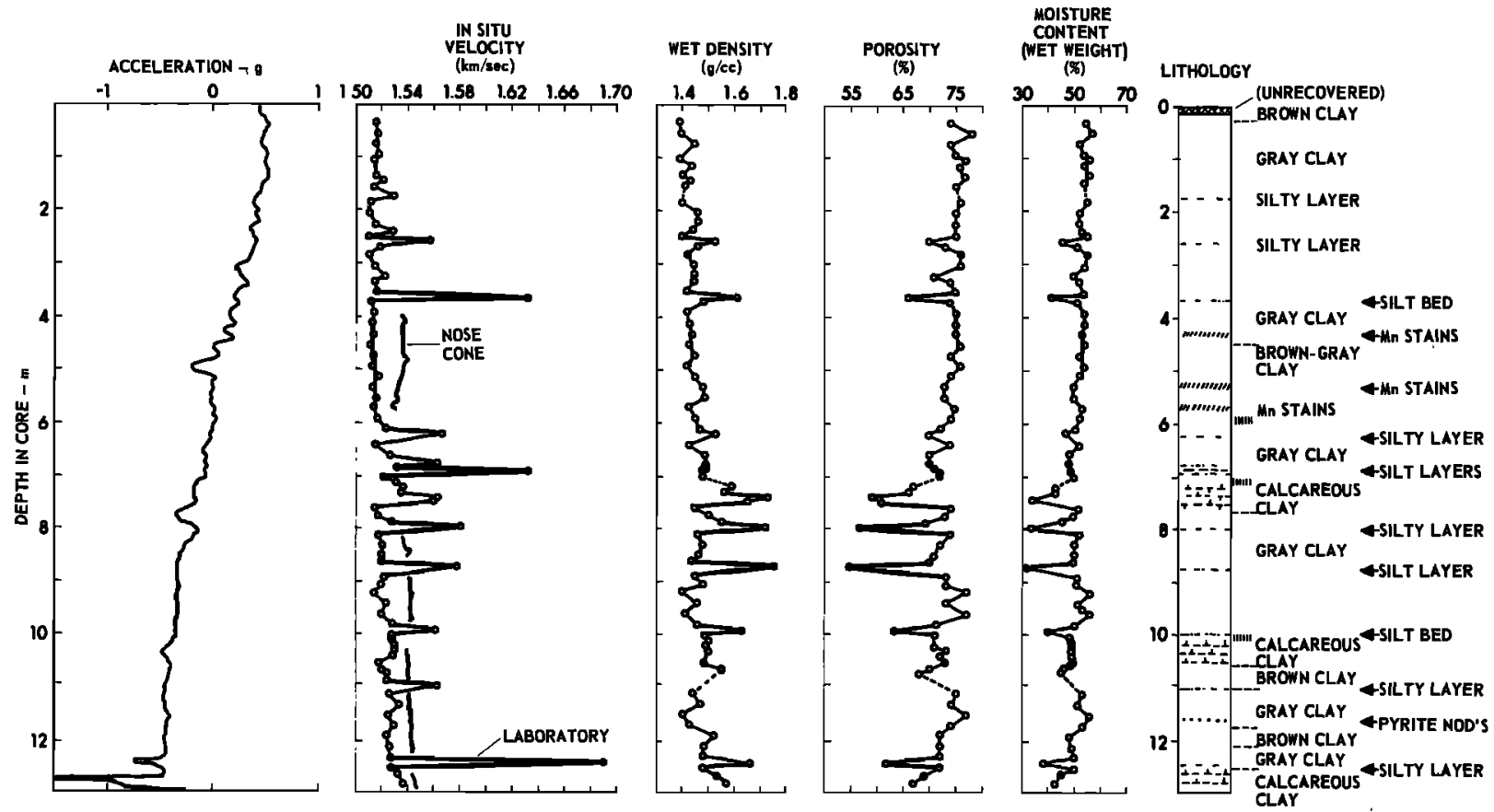

Fig. 7. Measured parameters for core RC19-20 from the western Nares Abyssal Plain. Explanation in Figure 5.

showed that signal levels were too low for accurate sound speed measurements. These data dropouts are caused by highspeed clay or silt beds that are thinner than the size of the transducer elements (approximately $2 \mathrm{~cm}$ ). Laboratory experiments indicate that when such layers are insonified between the transducers, the interference caused by the sound travelling at two different speeds can cause the amplitude of the pulse to drop below measurement level, thus causing errors in the indicated sound speed. In the clayey cores from the Bermuda Rise and the Greater Antilles Outer Ridge, many of these data dropouts appear to be caused by thin $(<1 \mathrm{~mm})$ hard clay laminae. The problem is greatly accentuated by the addition of numerous, thin high-velocity silt laminae in the abyssal plain cores. Another problem during the course of the shipboard experiments was cracking under pressure of the plastic that encapsulates the nose-cone transducers. This caused the transducer sensitivity to decrease, and the performance of the profilometer gradually degraded as coring progressed. New transducers were mounted between cores 14 and 15 so that performance was better for the next three cores. However by

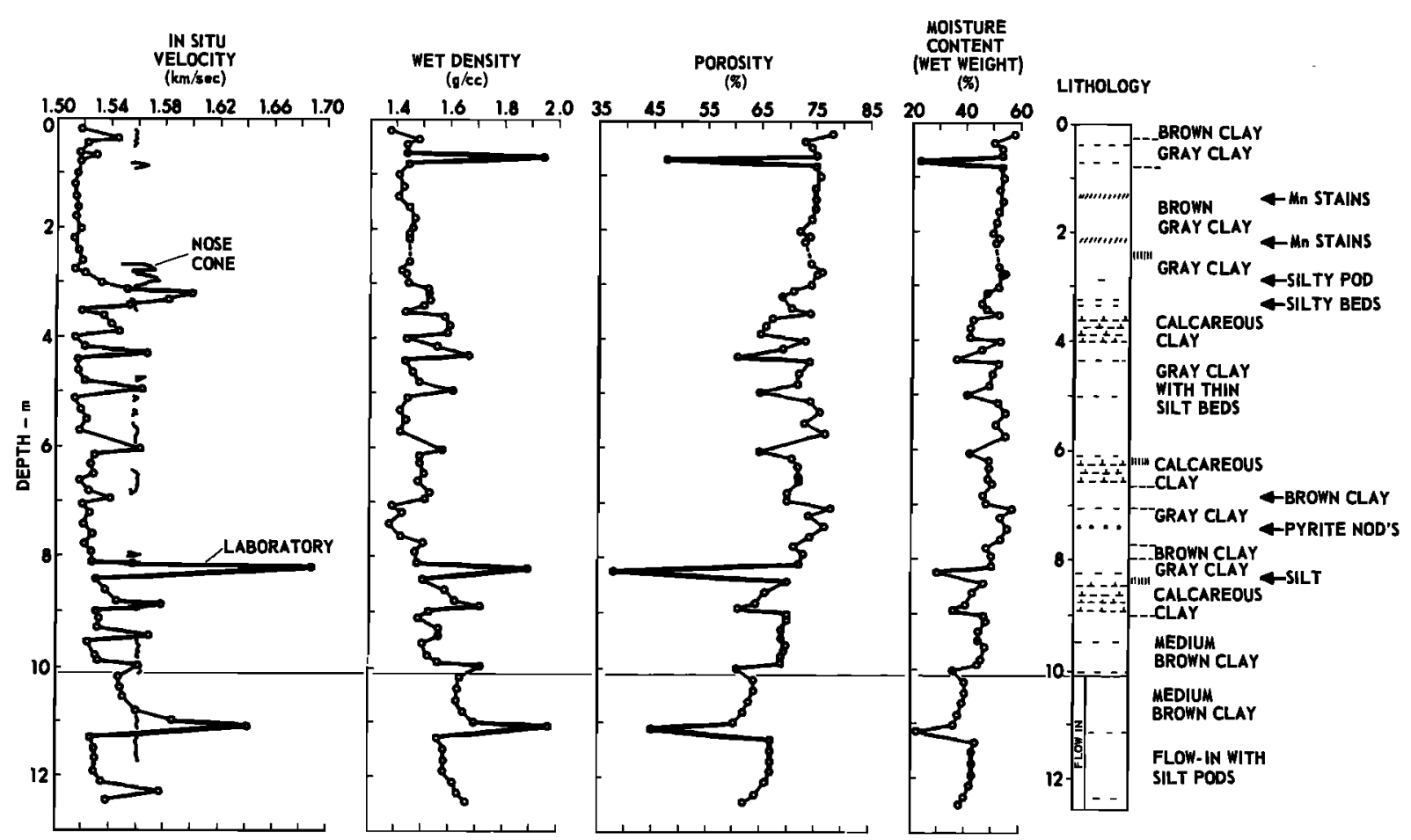

Fig. 8. Measured parameters for core RC19-21 from the western Nares Abyssal Plain. Explanation in Figure 5. 
TABLE 2. Properties of 'Undisturbed' and Remolded Samples From Gravity Core RC19-23

\begin{tabular}{|c|c|c|c|c|c|c|c|}
\hline \multirow{3}{*}{$\begin{array}{l}\text { Depth, } \\
\text { cm }\end{array}$} & \multicolumn{3}{|c|}{ Velocity, ${ }^{*} \mathrm{~m} / \mathrm{s}$} & \multirow{2}{*}{\multicolumn{2}{|c|}{ Wet Density, $\mathrm{g} / \mathrm{cc}$}} & \multirow{2}{*}{\multicolumn{2}{|c|}{ Wet Water Content, $\%$}} \\
\hline & \multirow{2}{*}{$\begin{array}{c}\text { Perpendicular } \\
\text { Beds }\end{array}$} & \multirow{2}{*}{$\begin{array}{l}\text { Parallel } \\
\text { Beds }\end{array}$} & \multirow[b]{2}{*}{ Remolded } & & & & \\
\hline & & & & 'Undisturbed' & Remolded & 'Undisturbed' & Remolded \\
\hline 5 & 1517 & 1517 & 1517 & 1.43 & 1.44 & 53 & 53 \\
\hline 15 & 1517 & 1518 & 1516,1518 & 1.43 & 1.44 & 53 & 52 \\
\hline 45 & 1516 & 1518 & 1518 & 1.45 & 1.43 & 53 & 54 \\
\hline 85 & 1517 & 1520 & 1521 & 1.34 & 1.36 & 59 & 59 \\
\hline 130 & 1517 & 1518 & 1516 & 1.45 & 1.43 & 52 & 53 \\
\hline
\end{tabular}

${ }^{*}$ Corrected to in situ conditions: $5932-\mathrm{m}$ water depth, $2.08^{\circ} \mathrm{C}$, salinity $34.85 \%$. Location: $23^{\circ} 42.7^{\prime} \mathrm{N}$, $60^{\circ} 03.6^{\prime} \mathrm{W}$

the time core 20 was taken, these transducers also were causing excessive dropouts.

The profilometer measurements are very similar to those made earlier near the South American continental margin [Shirley and Anderson, 1974, 1975]. In many of those cores however, the high-speed layers were relatively thick so that they were measured by the profilometer system. In other instances data dropouts occurred, and in the absence of laboratory measurements for comparison, these were thought to be actual low-speed layers. The cores showed velocity gradients in the range $1-2 s^{-1}$, comparable to the North Atlantic measurements.

The profilometer measurements in the North Atlantic also do not record the same detail of velocity variations observed in laboratory measurements. However, the remarkable core-tocore correlation of even small velocity variations in the laboratory measurements clearly shows that these variations are real and not simply an artifact of coring disturbance (Figures 9 and 10). Whether each of the various sediment types (clay, calcareous clay, silt, etc.) has suffered coring disturbance that brings its velocities to some uniform threshold value is un- known, but it is a possible explanation for the apparent difference in sensitivity of the profilometer measurements and the laboratory measurements. It should be pointed out that laboratory velocities of thin beds are minimum values and may vary from core to core. This occurs because of the fixed $(5 \mathrm{~cm})$ probe spacing which commonly results in the bed as well as additional sediment being measured; thus core-to-core changes in thickness of the same bed result in measurement of different velocities.

The validity of both laboratory and profilometer velocities can be checked against independent measurements of velocity and velocity gradient determined by near-bottom wide-angle reflection measurements. These high-resolution measurements were made in the fashion of standard sonobuoy recording, but with a seafloor hydrophone receiver and a $3.5 \mathrm{kHz}$ sound source about 6-12 m off the seafloor. On the Bermuda Rise and eastern Nares Abyssal Plain, velocities of $1.52 \pm 0.04 \mathrm{~km} /$ $\mathrm{s}$ and gradients of about $1 \mathrm{~s}^{-1}$ characterize the upper 20-30 m of sediment (G. Bryan and P. Hoose, unpublished data, 1977]. Although these measurements are not as precise as those on the piston cores, they offer much better resolution than stan-

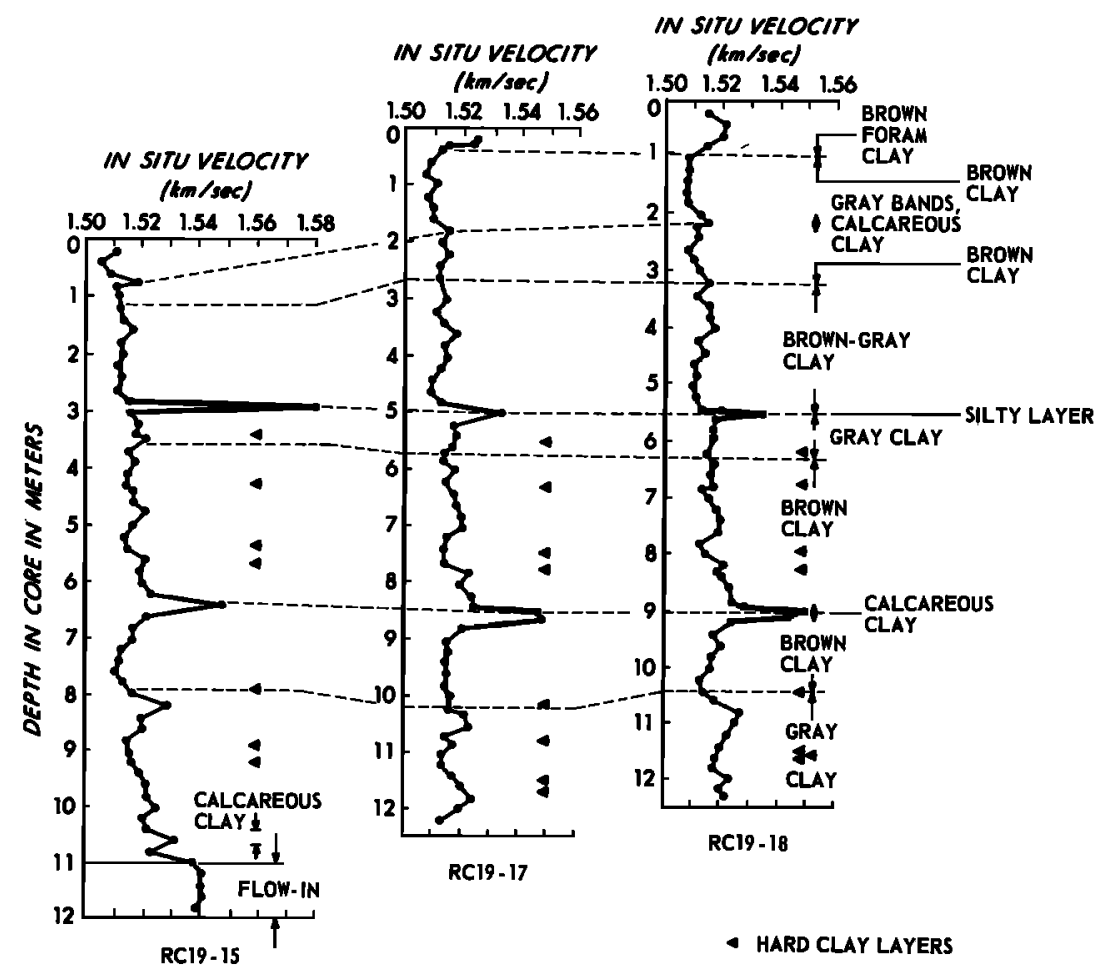

Fig. 9. Comparison of laboratory compressional wave velocities, corrected to in situ conditions, for three cores from the Greater Antilles Outer Ridge. 


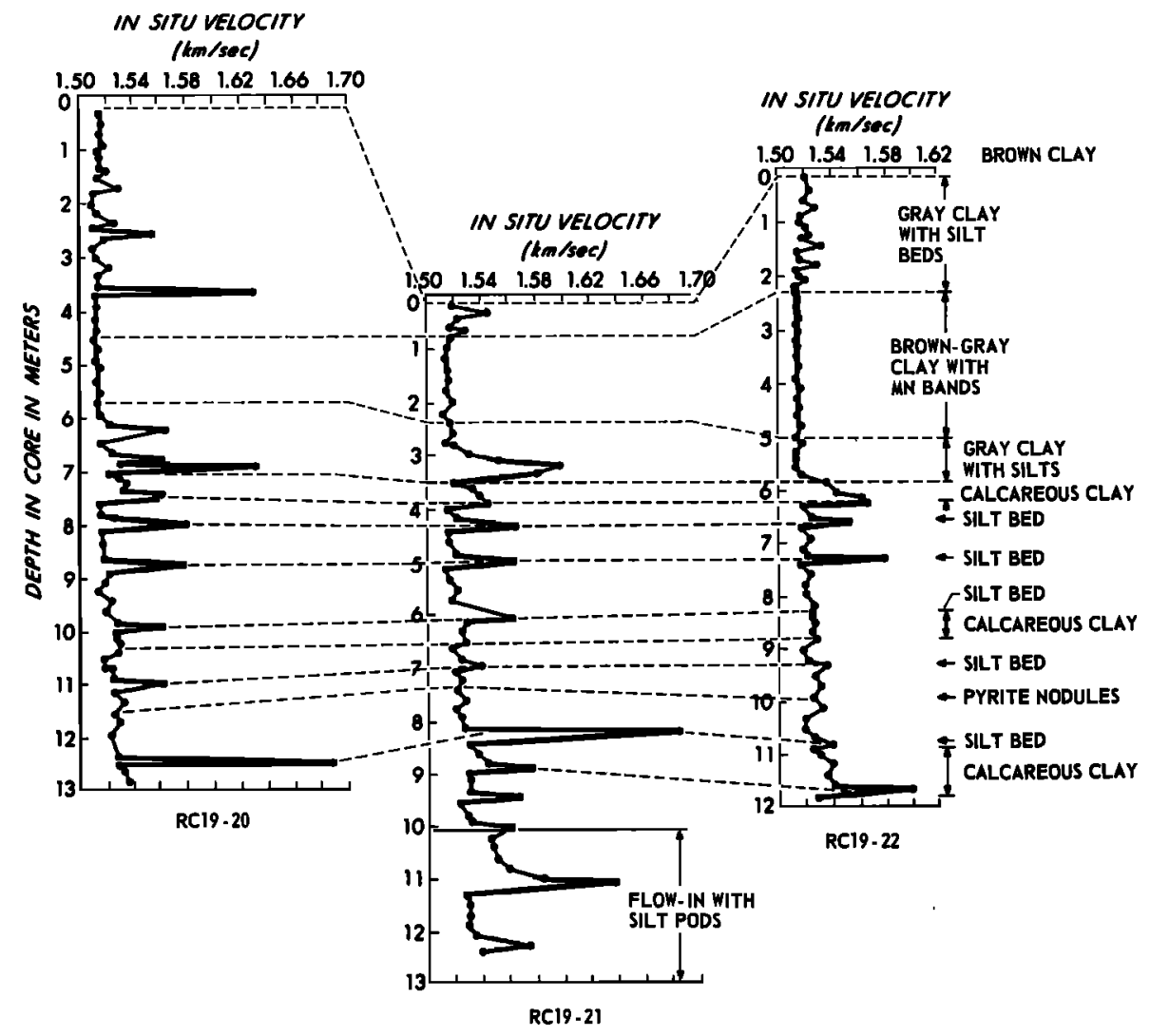

Fig. 10. Comparison of laboratory compressional wave velocities, corrected to in situ conditions, for three cores from the western Nares Abyssal Plain.

dard sonobuoy recordings and they confirm the general accuracy of the profilometer and laboratory velocities.

One interesting observation made possible by the core-tocore correlation of velocities, bulk properties and lithology is that lithologic intervals sometimes are missing or shortened in some cores. Because of the match of trigger-core to piston-core tops and because of the similar penetration history of the cores (Figures 4-8), it is unlikely that the missing or shortened zones are an artifact of coring. In the outer ridge cores, intervals about 0.5-1.5 m locally are absent (Figure 9), and they probably result from differential deposition controlled by bottom currents [Tucholke, 1975]. Intervals a few cm to more than $3 \mathrm{~m}$ thick are missing in some of the cores from the Nares Abyssal Plain (Figure 10). In these cores the missing intervals probably reflect shifts in the depositional loci of distal turbidity currents, perhaps because of migration of dispersive channels.

Detailed analysis of the relationships between velocities and bulk properties of these and other cores will be reported in a separate paper, but some general observations are made here. As expected, the higher velocity terrigenous silt beds in cores RC19-20 and 21 from Nares Abyssal Plain (Figures 7 and 8) normally have greater bulk densities and lower porosities and water contents than adjacent clays. A similar correlation generally is observed for the more subtle velocity variations in clayey sediments of the Bermuda Rise and Greater Antilles Outer Ridge (Figures 3-6). However, calcareous clays in all cores do not always show a distinct correlation with velocity. This may be due to grain-size variations in the calcareous fraction, which is composed of variable quantities of sand- and silt-size foraminifera, and fine-silt and clay-size nannoplankton and micritic calcite. Grain-size analyses have not yet been performed on these cores, but it is probable that mean grainsize exerts the strongest influence on velocity variations [Horn et al., 1968; Hamilton, 1970b]. The fact that there are significant downcore changes in the bulk properties and textural parameters supports the general validity of the velocity variations measured in the laboratory.

\section{Conclusions}

Comparison of in situ and laboratory measurements of sediment velocities in piston-core samples shows reasonable agreement for average velocities and velocity gradients, and the velocities are in the same range as those measured independently by near-bottom wide-angle reflection methods. In situ profilometer measurements consistently are $10-12 \mathrm{~m} / \mathrm{s}$ faster than laboratory measurements corrected to in situ conditions for clayey sediments, and $15-20 \mathrm{~m} / \mathrm{s}$ faster for turbidites. This may be caused by coring disturbance which reduces the dynamic frame bulk modulus $\left(k_{f}\right)$ of the sediment, the dynamic shear modulus $(G)$, or both. Laboratory measurements of velocity in undisturbed and remolded clayey sediments indicate that if this concept is valid, then these parameters probably are reduced to some minimum threshold value and additional distortion has no further effect. The in situ profilometer is of value in accurately determining average sediment velocities and velocity gradient, but it does not adequately sample thin, higher velocity beds.

In three closely spaced $(<12 \mathrm{~km})$ piston cores from each of two distinct morphologic provinces, marker beds which can be traced from core to core exhibit similar velocities and bulk properties. Thus the properties determined on a single core sample probably can be used to predict the properties in a 
given province of uniform morphology and acoustic character. However, local depositional or possibly erosional patterns can result in lateral discontinuity of small lithologic intervals. Such lateral discontinuities might be mapped best by high-frequency profiling ( 3.5 and $12 \mathrm{kHz}$ ) from a surface ship, provided the zones are thick enough to resolve $(>1 \mathrm{~m})$ and have detectable impedance contrasts.

Acknowledgments. We thank Robert Stoll, Robert Embley, and Edwin L. Hamilton for discussions and review of the manuscript. At Lamont-Doherty Geological Observatory the study of acoustic and physical properties of sea-floor sediments is supported by the Office of Naval Research under contract N00014-75-C-0210, and at Applied Research Laboratories, University of Texas, by ONR contract N00014-76-C-0117. We also thank J. Kostecki, G. Bryan, and the Captain and crew of R/V Conrad for their help in shipboard operations. Contribution 2757 of Lamont-Doherty Geological Observatory.

\section{REFERENCES}

Hamilton, E. L., Sound velocity and related properties of marine sediments, North Pacific, J. Geophys. Res., 75, 4423-4445, 1970a.

Hamilton, E. L., Prediction of in-situ acoustic and elastic properties of marine sediments, Geophysics, 36, 266-283, $1970 b$.

Hamilton, E. L., H. P. Bucker, D. L. Keir, and J. A. Whitney, Velocities of compressional and shear waves in marine sediments determined in situ from a research submersible, J. Geophys. Res., 75 , $4039-4049,1970$.
Horn, D. R., B. M. Horn, and M. N. Delach, Correlation between acoustical and other physical properties of deep-sea cores, $J$. Geophys. Res., 73, 1939-1957, 1968.

Houtz, R. E., and J. I. Ewing, Detailed sedimentary velocities from seismic reflection profiles in the western North Atlantic, J. Geophys. Res., 58, 5233-5258, 1963.

Le Pichon, X., J. I. Ewing, and R. E. Houtz, Deep-sea sediment velocity determination made while reflecting profiling, $J$. Geophys. Res.. 73, 2597-2614, 1968.

U.S. Naval Oceanographic Office, Tables of sound speed in seawater, Navoceano SP58, 47 pp., Washington, D. C., 1962.

Shirley, D. J., and A. L. Anderson, Compressional-wave profilometer for deep-water measurements, $A R L-T R-74-51,82 \mathrm{pp}$., Appl. Res. Lab., Univ. of Tex., Austin, 1974.

Shirley, D. J., and A. L. Anderson, In situ measurements of marine sediment acoustical properties during coring in deep water, IEEE Trans. Geosci. Electron., GE-I3(4), 163-169, 1975.

Shirley, D. J., and A. L. Anderson, Shear waves in unconsolidated sediments, paper presented at 92nd Annual Meeting, Acoust. Soc. of Amer., San Diego, Calif., 1976.

Tucholke, B. E., Sediment distribution and deposition by the Western Boundary Undercurrent: The Greater Antilles Outer Ridge, $J$. Geol., 83, 177-207, 1975 .

(Received February 7, 1978;

revised August 2, 1978;

accepted September 7, 1978.) 